\title{
Factors Influencing the Presence of Interproximal Dental Papillae between Maxillary Anterior Teeth: A Clinical and Radiographic Study of the Indian Population
}

\author{
Nikhil Jain, Ramandeep Dugal, Mohit Kheur, Smita Musani
}

\begin{abstract}
Introduction: The presence of a normal and harmonically shaped papilla is crucial to avoid the presence of the 'black triangle' which is of major esthetic concern. The distance from the alveolar bone crest $(\mathrm{BC})$ to the base of the contact area $(\mathrm{CP})$ is a significant factor in determining whether a papilla will fill the interdental space.
\end{abstract}

Aim: To correlate the BC-CP distance with a different anatomic variable using a noninvasive method and to describe a simple, repeatable, observational measuring protocol to contribute to the prosthetic and surgical treatment planning.

Materials and methods: A total of 63 patients were enrolled in the study. A digital radiographs of the interdental embrasure between teeth 12 and 11,11 and 21 and teeth 21 and 22 were taken with a paralleling cone technique using a RINN film holder. The radiographic data was used to measure the distance between the contact point and the bone crest (BC-CP) and the interdental distance (IDD) at the level of the bone crest.

Results: The number of papillae that filled the interproximal space decreased with the increasing BC-CP and IDD distance.

Conclusion: The vertical and horizontal dimensions of the interdental space influence the existence of interdental papilla.

Keywords: Black triangle, Tarnow, Dental papilla, Gingiva, Dental esthetics.

How to cite this article: Jain N, Dugal R, Kheur M, Musani S. Factors Influencing the Presence of Interproximal Dental Papillae between Maxillary Anterior Teeth: A Clinical and Radiographic Study of the Indian Population. World J Dent 2013;4(3):158-163.

\section{Source of support: Nil}

Conflict of interest: None declared

\section{INTRODUCTION}

The interdental papilla, which occupies the interdental space, not only acts as a barrier in protecting the periodontal structures but also plays a critical esthetic role. ${ }^{1}$ The presence of a papilla and the preservation of this structure, particularly in the interdental area between the maxillary incisors, the most visible portion of the teeth, is an important concern in esthetic dentistry. ${ }^{2}$ The existence of a space below the contact area can result in esthetic impairment, phonic problems and food impaction. ${ }^{3,4}$ The presence of a normal and harmonically shaped papilla is crucial to avoid the presence of the 'black triangle' which is of major concern to prosthodontists, periodontists and patients.
A number of studies ${ }^{4-7}$ have been performed to discover the factors leading to the complete or incomplete regeneration of the papilla. It has long been known that the distance from the contact point (CP) to the alveolar bone crest (BC) is a significant factor in determining whether a papilla will fill the interdental space. ${ }^{8-11}$ In 1992, Tarnow et $\mathrm{al}^{4}$ reported that when the BC-CP distance was $\leq 5 \mathrm{~mm}$, the papilla was almost always present; when the distance was $\geq 7 \mathrm{~mm}$, the papilla was usually absent. Age and interdental distance (IDD) were also cited as potential factors. ${ }^{8-11}$ A rectangular-shaped crown form was shown to be associated with the presence of interdental papillae. ${ }^{12}$ In addition, other factors, such as angulation of the roots of adjacent teeth, the volume of the embrasure space, embrasure area, papilla length, keratinized gingival width and the course of the cementoenamel junction (CEJ), have been investigated and found to help determine whether the interdental papilla will be present. ${ }^{3,4,6,12}$

Previous studies ${ }^{7,13}$ of determinants of papilla presence were hampered by the need to use local anesthesia and a dental probe to determine the distance of the crest of the underlying bone from the papilla tip. In the present study, a noninvasive method is used. A radiograph is taken to measure the parameters of interest and, thus, avoid the difficulties and potential lack of subject acceptance of the more invasive method.

A constant relation of Tarnow's principle has been found in the foreign population, inspite of which there arises a need to check if they are applicable to the Indian population as we differ from foreigners, genetically and also racially. Hence, one of the objectives of this study is to determine if Tarnow's principles are applicable to the Indian population as well.

Identifying factors related to the presence of interdental papilla will be useful for preventing and managing the loss of interdental papillae. Therefore the aim of this study is to confirm the data in the literature correlating the BC-CP distance with a different anatomic variable using a noninvasive method and to describe a simple, repeatable, observational measuring protocol to contribute to the prosthetic and surgical decision making.

From an anatomic and histological point of view, the anterior papilla is quite different from the posterior 
interproximal papilla. Also, contact points are different in anterior regions. For this reason, we studied only anterior esthetic areas represented by the four maxillary incisors to have a homogeneous sample.

\section{MATERIALS AND METHODS}

\section{Subject Selection}

A total of 63 patients, 36 males and 27 females, who visited MA, Rangoonwala Dental College and Hospital, Pune in 2012 were enrolled in this study. All patients provided informed consent. The mean age was 42.4 years, ranging from 19 to 64 . A total of 154 interdental areas were measured. All the patients had undergone initial therapy including oral hygiene instructions and ultrasonic scaling of the entire dentition. The following conditions that could affect the existence and healthy status of the interdental papillae were excluded: (1) areas with a prior history of periodontal surgery; (2) a root that was rotated or had concavities interproximally; (3) areas with no interdental contacts; (4) orthodontically treated areas; and (5) translocated or tilted teeth.

\section{Determination of the Existence of Interdental Papillae}

For visibility, selected interdental papillae were completely dried to remove saliva. Interdental papillae were then divided into the following two categories by identifying the black triangles between the teeth: (1) papillae were present when interdental papillae completely filled to the entire proximal space; and (2) papillae were absent when they did not extend all the way up to the contact point and there was a 'black triangle' below the contact point.

\section{Radiographic Measurements}

A digital radiograph of the interdental embrasure between teeth 12 and 11, 11 and 21 and teeth 21 and 22 were taken with a paralleling cone technique using a RINN film holder (Fig. 1). The radiographic data was used to measure the distance between the contact point and the bone crest (BC$\mathrm{CP}$ ) and the interdental distance (IDD) at the level of the bone crest.

All the radiographs are standardized using the same digital RVG machine, software and exposure parameters. A 19 gauge orthodontic wire, $10 \mathrm{~mm}$ in length as measured on a digital vernier caliper was stuck onto the digital sensor using carding wax to calibrate the measurements on the software (Fig. 2). The digital radiographs stored in JPEG format were then transferred onto another digital software (Suni Ray) to enhance the image by colorizing, zoom and
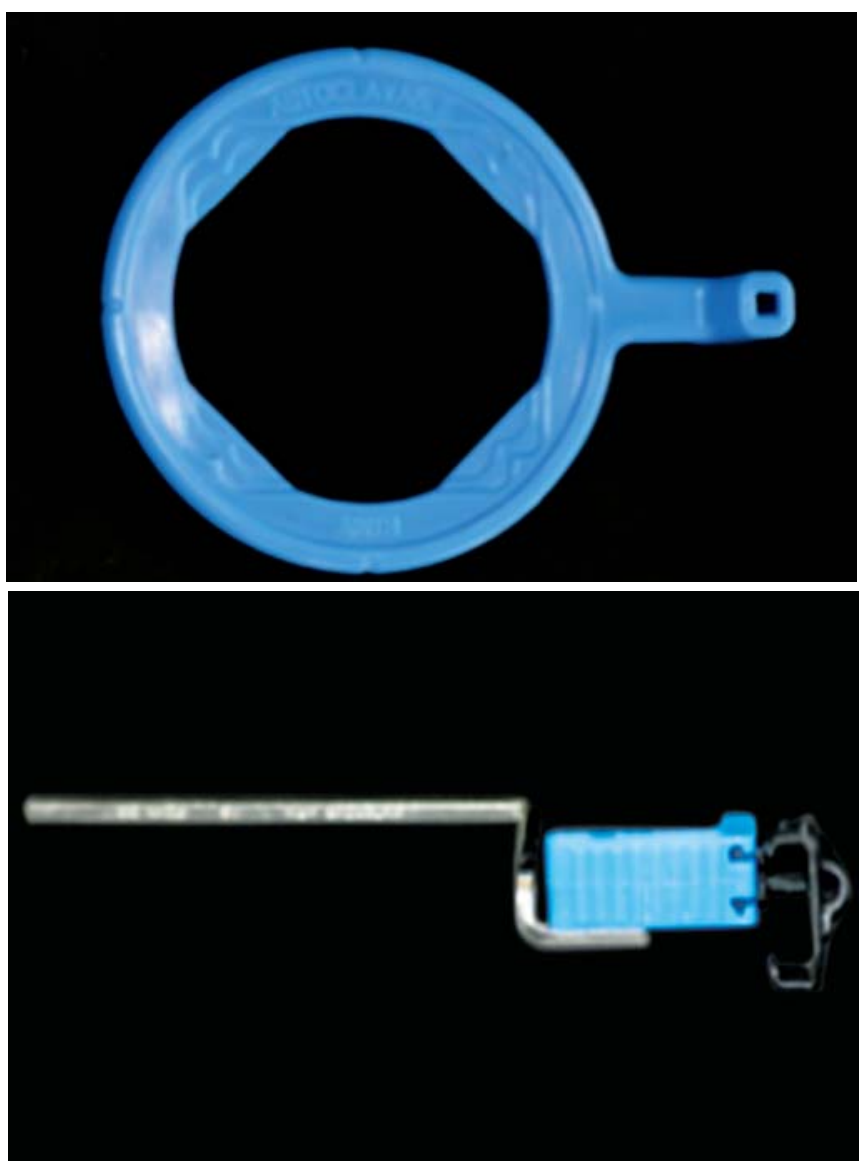

Fig. 1: RINN film holder

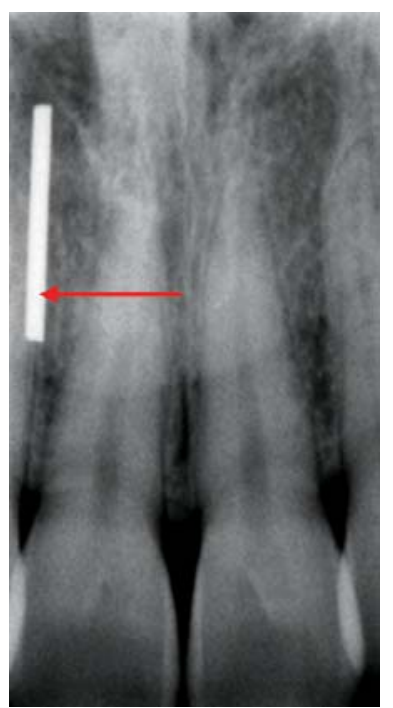

Fig. 2: A 19 gauge orthodontic wire, $10 \mathrm{~mm}$ in length

sharpen border tools (Fig. 3). BC-CP and IDD were hence calculated on the software.

\section{The Distance from the Contact Point to Alveolar Crests}

The vertical dimension between the alveolar crest closest to the occlusal side and the lowest point of contact surface between the teeth was measured (Fig. 4A). 


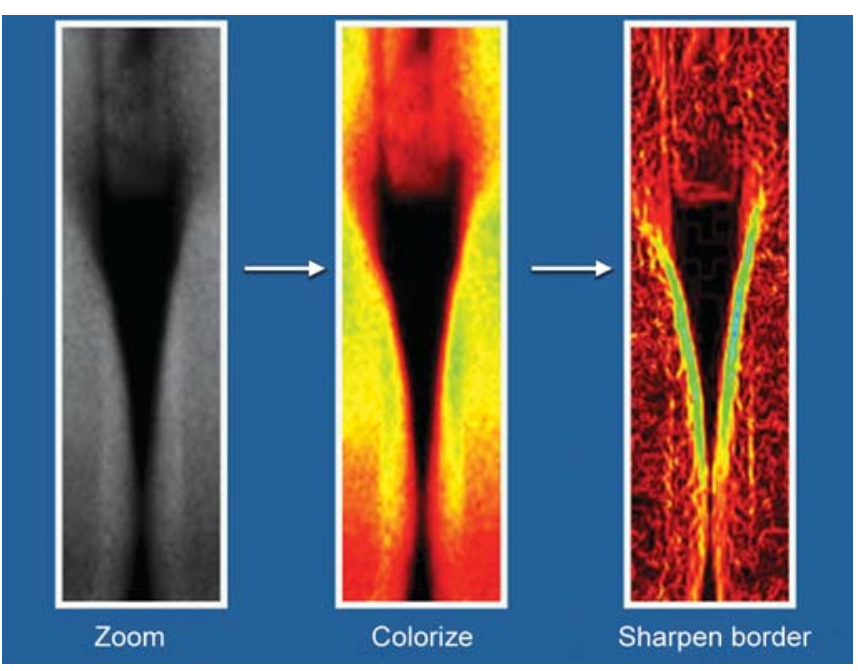

Fig. 3: Enhancing the image by colorizing, zoom and sharpen border tools

\section{Interproximal Distance Between Roots}

After measuring the vertical dimension, the interproximal distance of roots at the highest alveolar crest levels were measured. The distance between the distal surface of the mesial tooth and the mesial surface of the distal tooth was measured (Fig. 4B).

\section{RESULTS}

\section{Existence of Interdental Papillae According to Various Distances from the Alveolar Bone Crest to the Contact Point (BC-CP)}

Existence of interdental papillae in 94.7\% (19/20) of cases when the BC-CP distance was $3 \mathrm{~mm}, 89.2 \%$ (33/37) of cases when the BC-CP distance was $4 \mathrm{~mm}, 85.4 \%$ (35/41) of cases when the BC-CP distance was $5 \mathrm{~mm}, 77.3 \%$ (17/ 23) of cases when the BC-CP distance was $4 \mathrm{~mm}, 85.4 \%$ (35/41) of cases when the BC-CP distance was $6 \mathrm{~mm}, 89.2 \%$ (33/37) of cases when the BC-CP distance was $4 \mathrm{~mm}, 30.8 \%$ (11/20) of cases when the BC-CP distance was $7 \mathrm{~mm}$ and

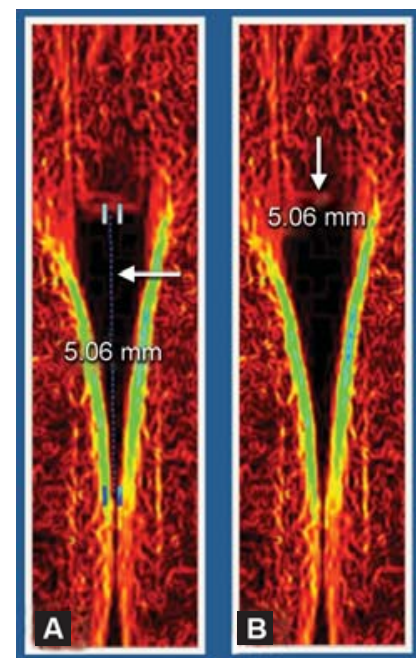

Figs 4A and $B$ : $(A)$ The distance from the contact point to alveolar crests (BC-CP), (B) interproximal distance between roots (IDD)

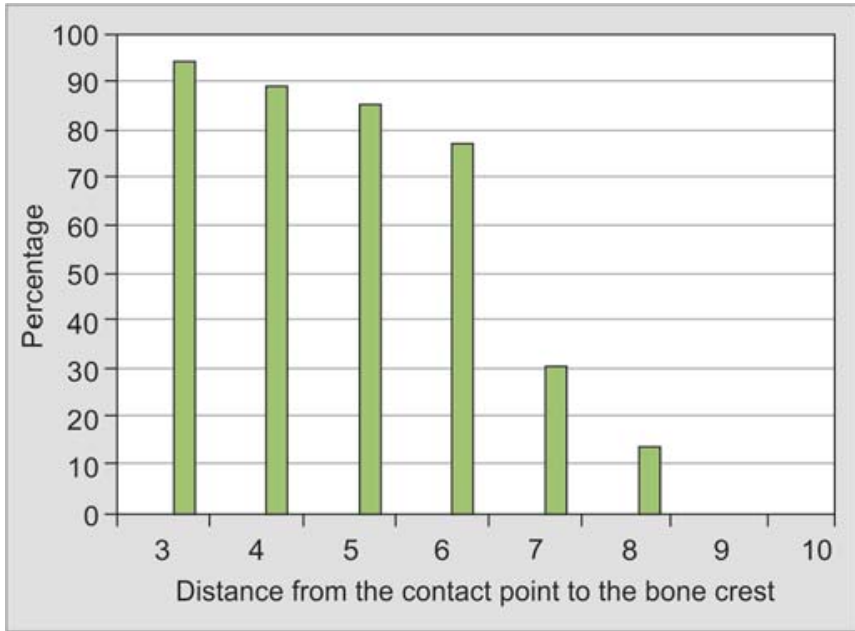

Graph 1: The percentage of present papillae according to various distances from the contact point to the alveolar crest

$<15 \%(1 / 13)$ when the distance was $>7 \mathrm{~mm}$ (Table 1$)$. Therefore, the number of papillae that filled the interproximal space decreased with the increasing BC-CP distance, which was statistically significant $(\mathrm{p}<0.5)$ (Table 1 and Graph 1).

Table 1: Existence of interdental papillae according to various distances from the contact point to the alveolar crest

\begin{tabular}{|c|c|c|c|c|c|c|c|c|}
\hline & \multicolumn{8}{|c|}{ Distance (mm) (total N papillae) 36/154 } \\
\hline & $3(20)$ & $4(37)$ & $5(41)$ & $6(23)$ & $7(20)$ & $8(8)$ & $9(3)$ & $10(2)$ \\
\hline Present & 19 & 33 & 35 & 17 & 11 & 1 & 0 & 0 \\
\hline Absent & 1 & 4 & 6 & 5 & 9 & 6 & 3 & 2 \\
\hline Present(\%) & 94.7 & 89.2 & 85.4 & 77.3 & 30.8 & 14.3 & 0 & 0 \\
\hline
\end{tabular}

Table 2: Existence of interdental papillae according to various interproximal distances of roots

\begin{tabular}{lcccccccccc}
\hline & \multicolumn{1}{c}{ Distance $(\mathrm{mm})$ (total N papillae) } \\
\cline { 2 - 10 } & $1(7)$ & $1.5(32)$ & $2(43)$ & $2.5(26)$ & $3(22)$ & $3.5(13)$ & $4(9)$ & $4.5(1)$ & $5(1)$ \\
\hline Present & 6 & 28 & 35 & 19 & 16 & 2 & 3 & 0 & 0 \\
Absent & 1 & 4 & 6 & 7 & 6 & 6 & 4 & 1 & 1 \\
Present(\%) & 85.7 & 87.5 & 85.7 & 73 & 72.7 & 25 & 33.3 & 0 & 0 \\
\hline
\end{tabular}


Existence of Interdental Papillae According to Various Interproximal Distances between Roots (IDD)

Existence of interdental papillae were present in $85.7 \%(6 / 7)$ of cases when the IDD was $1 \mathrm{~mm}, 87.5 \%$ (28/32) of cases when the IDD was $1.5 \mathrm{~mm}, 85.7 \%$ (35/43) of cases when the IDD was $2.0 \mathrm{~mm}, 73 \%$ (19/26) of cases when the IDD was $2.5 \mathrm{~mm}, 72.7 \%(16 / 22)$ of cases when the IDD was $3.0 \mathrm{~mm}$, and $25 \%(2 / 13)$ of cases when the IDD was $3.5 \mathrm{~mm}$, $33.3 \%$ (3/9) of cases when the IDD was $4 \mathrm{~mm}$ and the papilla was always lost when the interproximal distance of roots was more than $4 \mathrm{~mm}$ (Table 2). Therefore, the number of papillae that filled the interproximal space decreased with the increasing interproximal distance of the roots, which was statistically significant $(\mathrm{p}<0.05)$ (Table 2 and Graph 2).

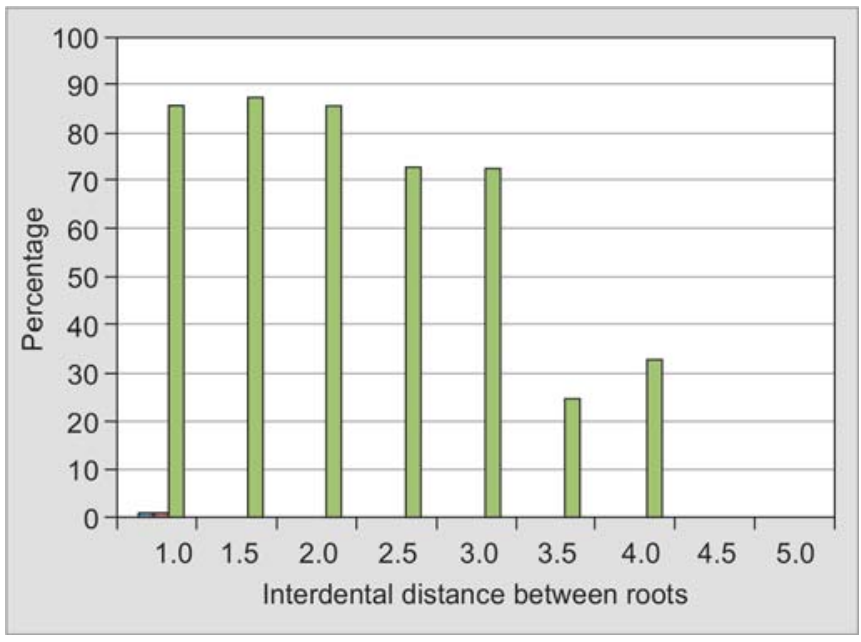

Graph 2: The percentage of present papillae according to various interproximal distances between roots
Table 4: Interrelation between the interproximal distance between roots (IDD) and the distance from the contact point to the alveolar crest

\begin{tabular}{lcc}
\hline$I D D(\mathrm{~mm})$ & $N$ sites & Mean $\pm S D(\mathrm{~mm})$ \\
\hline 1 & 7 & $3.8 \pm 0.8$ \\
1.5 & 32 & $4.9 \pm 1.8$ \\
2 & 43 & $5.1 \pm 2.1$ \\
2.5 & 26 & $5.0 \pm 3.6$ \\
3 & 22 & $5.3 \pm 4.2$ \\
3.5 & 13 & $5.8 \pm 1.7$ \\
4 & 9 & $6.3 \pm 2.3$ \\
4.5 & 1 & $10 \pm 0.0$ \\
5 & 1 & $9 \pm 0.0$ \\
\hline
\end{tabular}

\section{Existence of Interdental Papillae According to} the Bone Crest-Contact Point Distance (BC-CP), Depending on the Various Interproximal Distances of Roots (IDD)

In each distance from the bone crest to the contact point, the number of papillae that filled the interproximal space decreased with the increasing interproximal distance between the roots (Tables 3 and 4).

\section{DISCUSSION}

Based on the literature, the presence of interdental papillae is affected by the level of the alveolar crests in the interdental space. However, there are no reports on the intimate relationship between the horizontal dimension and the presence of papillae. Therefore, our study included interproximal distance of roots, which is the horizontal factor.

Table 3: The percentage of papillae present according to the interproximal distance between roots (IDD) and the distance from the contact point to the alveolar crest

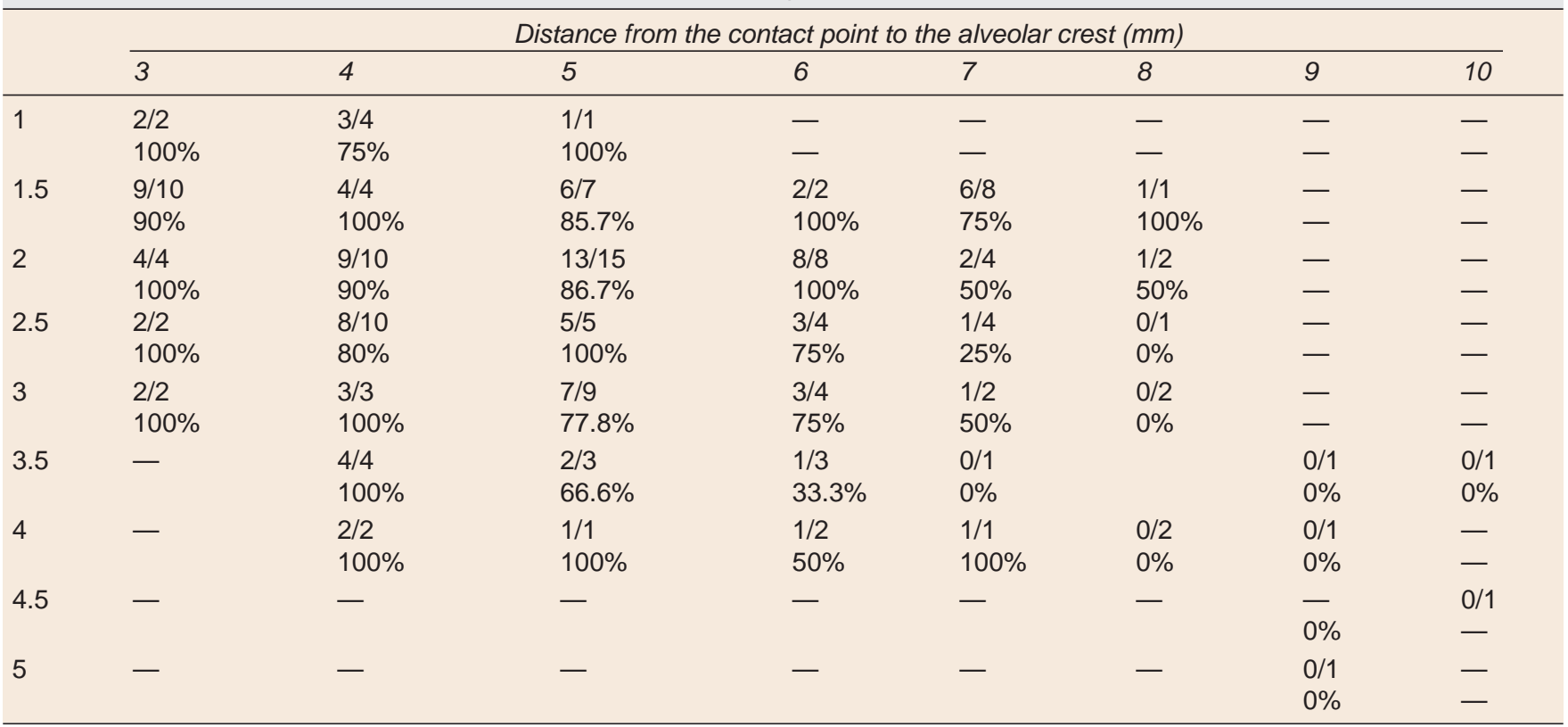


In this study, the most common distance between two roots was $2 \mathrm{~mm}$. When the distance between two roots was $2 \mathrm{~mm}$, the average distance between a contact point and the alveolar crest was $5.1 \mathrm{~mm}$.

When the interdental space had undergone previous periodontal surgery, $\mathrm{Tal}^{14}$ reported that a scar can be formed in the interdental soft tissue, the col can be removed below the interdental contacts, and the fiber groups can be rearranged or severed. Takei ${ }^{15}$ reported that the contact points in the areas with transpositioned or tilted teeth can be difficult to measure, and the denaturation of papillae was expected from frequent inflammation by food impaction. Therefore, in this study, the previous periodontal surgery area and a root that was rotated or had concavities interproximally, were excluded because they can cause measurement errors. Orthodontically treated areas were also excluded because orthodontic treatment can artificially suppress the interdental soft tissue, deform interdental papillae, and reshape the interdental contact area. All areas with any inflammation were excluded because the swelling can cause errors.

In this study, the bone crest - contact point distance and the interdental distance were measured by a noninvasive method on a digital radiograph. This method is different from those reported in other studies using different invasive methods like raising a mucoperiosteal flap.

Salama et $\mathrm{al}^{16}$ suggested that the interdental distance can change the form of the interdental soft tissue and alveolar bone. Heins and Wieder ${ }^{17}$ reported that interradicular bone with a long interproximal distance between roots has more cancellous bone and is more reactive to external forces and inflammation. Moscow et $\mathrm{al}^{18}$ also reported that the number of papillae present decreases with the increasing BC-CP distance.

In this study, there was no root area that showed the interproximal distance of 1.6 or $1.7 \mathrm{~mm}$. It was also found that when the BC-CP dimensions of 3 and $4 \mathrm{~mm}$ showed almost $100 \%$ papillae formation for interdental distance ranging from 1 to $4 \mathrm{~mm}$. This is important from restorative and orthodontic points of view when teeth are sometimes moved for esthetic reasons. However, in this study, according to the increase in the distance from the bone crest to the contact point, the number of papillae that filled the interproximal space decreased with the increasing interproximal distance between roots. It is believed that other factors can be considered. Further research will be needed.

\section{CONCLUSION}

The vertical and horizontal dimensions of interdental space can affect the shape as well as the maintenance of the interdental soft tissue, and the interproximal distance between roots and the distance from the contact point to the bone crest, which can represent the vertical and horizontal dimension, can affect the existence of papilla. Therefore, a thorough understanding of the anatomic form of the interdental space will be very useful in esthetic dental treatment and for predicting the treatment outcome.

\section{Manufacturer Name}

a. RINN film holder (Dentsply Maillefer, Ballaigues, Switzerland)

b. Digital RVG machine and software (SUNI, San Hose, USA).

\section{REFERENCES}

1. Tarnow DP, Eskow RN. Considerations for single-unit esthetic implant restorations. Compend Contin Educ Dent 1995;16: 778-788.

2. Kokich VG. Adjunctive role of orthodontic therapy. In: Newman MG, Takei HH, Klokkevold PR, Carranza FA, editors. Carranza's Clinical Periodontology, 10th ed. St Louis: Elsevier; 2006:856-870.

3. Prato GP, Rotundo R, Cortellini P, Tinti C, Azzi R. Interdental papilla management: a review and classification of the therapeutic approaches. Int J Periodontics Restorative Dent 2004;24:246-255.

4. Tarnow DP, Magner AW, Fletcher P. The effect of the distance from the contact point to the crest of bone on the presence or absence of the interproximal dental papilla. J Periodontol 1992;63:995-996.

5. Zetu L, Wang HL. Management of interdental/interimplant papilla. J Clin Periodontol 2005;32:831-839.

6. Gastaldo JF, Cury PR, Sendyk WR. Effect of the vertical and horizontal distances between adjacent implants and between a tooth and an implant on the incidence of interproximal papilla. J Periodontol 2004;75:1242-1246.

7. Choquet V, Hermans M, Adriaenssens P, Daelemans P, Tarnow DP, Malevz C. Clinical and radiographic evaluation of the papilla level adjacent to single-tooth dental implants. A retrospective study in the maxillary anterior region. J Periodontol 2001;72:1364-1371.

8. Cho HS, Jang HS, Kim DK, et al. The effects of interproximal distance between roots on the existence of interdental papillae according to the distance from the contact point to the alveolar crest. J Periodontol 2006;77:1651-1657.

9. Martegani P, Silvestri M, Mascarello F, et al. Morphometric study of the interproximal unit in the esthetic region to correlate anatomic variables affecting the aspect of soft tissue embrasure space. J Periodontol 2007;78:2260-2265.

10. Chang LC. The central papilla height in association with age and gender-assessed with a new method. Chin J Periodontol 2006;11:271-279.

11. Chang LC. The presence of a central papilla is associated with age but not gender. J Dent Sci 2006;1:161-167. 
12. Kurth JR, Kokich VG. Open gingival embrasure after orthodontic treatment in adults: prevalence and etiology. Am J Orthod Dentofacial Orthop 2001;120:116-123.

13. Tarnow D, Elianb N, Fletcher P, et al. Vertical distance from the crest of bone to the height of the interproximal papilla between adjacent implants. J Periodontol 2003;74: $1785-1788$.

14. Tal H. Relationship between the interproximal distance of roots and the prevalence of intrabony pockets. J Periodontol 1984;55:604-607.

15. Takei HH. The interdental space. Dent Clin North Am 1980;24:169-176.

16. Salama H, Salama MA, Garber D, Adar P. The interproximal height of bone: A guidepost to predictable aesthetic strategies and soft tissue contours in anterior tooth replacement. Pract Periodontics Aesthet Dent 1998;10:1131-1141.

17. Heins PJ, Wieder SM. A histologic study of the width and nature of inter-radicular spaces in human adult premolars and molars. J Dent Res 1986;65:948-951.

18. Moskow BS, Tannenbaum P, Bloom A. Visualization of the human periodontium using serial thin section contact radiography. J Periodontol 1985;56:223-233.

\section{ABOUT THE AUTHORS \\ Nikhil Jain (Corresponding Author)}

Postgraduate Student (3rd Year), Department of Prosthodontics and Implantology, MA Rangoonwala College of Dental Sciences and Research Centre, Pune, Maharashtra, India, Phone: 91-9975507714 e-mail: drnikhiljain@outlook.com

\section{Ramandeep Dugal}

Professor and Head, Department of Prosthodontics and Implantology MA Rangoonwala College of Dental Sciences and Research Centre Pune, Maharashtra, India

\section{Mohit Kheur}

Professor, Department of Prosthodontics and Implantology, MA Rangoonwala College of Dental Sciences and Research Centre, Pune Maharashtra, India

\section{Smita Musani}

Professor, Department of Prosthodontics and Implantology, MA Rangoonwala College of Dental Sciences and Research Centre, Pune Maharashtra, India 